\title{
A Ciência útil em O Patriota (Rio de Janeiro, 1813-1814)
}

\author{
Practical Science in “O Patriota” (Rio de Janeiro, 1813-1814)
}

\author{
LORELAI KURY \\ Fiocruz | Casa de Oswaldo Cruz
}

\begin{abstract}
RESUMO O periódico "O Patriota", publicado no Rio de Janeiro, em 1813 e 1814 teve como uma de sua principais características a publicação de artigos sobre as ciências e as artes. O periódico se insere no universo da imprensa das Luzes, no qual a utilidade deveria ser a base das ciências. As memórias publicadas em $\mathrm{O}$ Patriota demonstram que os textos se originam majoritariamente de funcionários civis e militares da Coroa, com formação na Europa. Em alguns casos, os textos resultam de experiências efetivamente realizadas, nos moldes do que se considerava científico na Europa. Em outros casos, os textos publicados são traduções e compilações, que pretendiam induzir as novas práticas iluministas.
\end{abstract}

Palavras-chave Iluminismo, história da Imprensa, Utilidade, O Patriota

\begin{abstract}
O Patriota"was a periodical published in Rio de Janeiro, in 1813 and 1814. One of its main characteristics was to publish articles on science and the arts. This journal has to be understood in the context of the Enlightenment Press, which considered utility as a principle of science. Texts published in "O Patriota" originated mainly from the work of military and civilian employees of the Crown, who had been trained in Europe. In some cases, the texts were the result of experiments effectively carried out, and should be considered as science, based on European standards from that time. In other cases, the texts published were translations and compilations, published in order to stimulate new practices from the Enlightenment.
\end{abstract}

Key words Enlightenment, History of Press, Utility, O Patriota

0 jornal 0 Patriota, publicado em 1813 e 1814 no Rio de Janeiro, ocupa lugar de destaque na história da imprensa no Brasil por ser uma das primeiras publicações seriadas locais. Além disso, o jornal teve como característica peculiar dedicar muito espaço às chamadas ciências e artes. Ao todo, foram publicados dezoito números do jornal, doze mensais, em 1813, e seis bimestrais em 1814. Seu editor, o baiano Manuel Ferreira de Araújo Guimarães (1778-1838), era, na época, o responsável pela Gazeta do Rio de Janeiro, espécie de órgão oficial do governo. Guimarães era diplomado pela Academia Real dos Guardas-Marinhas de Lisboa e foi lente da Academia Real Militar do Rio de Janeiro, desde sua criação, em 1810. 0 militar foi também responsável por diversas traduções de manuais de matemática, astronomia e geodésica para servirem ao ensino na Academia Militar. Ligado a D. Rodrigo de Sousa Coutinho, o editor de 0 Patriota, embora relativamente pouco estudado atualmente, foi personagem central da constituição da imprensa e das instituições científicas no Brasil nas primeiras décadas do século XIX. Guimarães era também poeta e crítico literário e de teatro. Esse perfil, que não chegava a ser incomum na época, tornava-o capaz de circular com segurança por diferentes temas e de editar um periódico enciclopédico. 
Durante dois anos, 0 Patriota publicou artigos que iam de notícias políticas europeias a listas de plantas medicinais brasileiras, cobrindo igualmente assuntos filosóficos e poesia. Considerado na conjuntura da llustração lusa e brasileira, o periódico se insere no universo temático das publicações do Arco do Cego, que tinham sido capitaneadas pelo religioso mineiro Mariano da Conceição Veloso, vinculado a Sousa Coutinho. Esse veio editorial é uma expressão portuguesa da produção das Luzes, tal como acontecia de forma geral na Europa e nas Américas.

Se a celebridade das Luzes na atualidade recaiu sobre alguns filósofos iconoclastas de expressão francesa, como Rousseau ou Diderot, a presença constante e cotidiana das novas práticas esclarecidas é bem exemplificada por temas aparentemente prosaicos e limitados como o plantio de batatas, a melhor maneira de construir cercas ou sobre criação de bichos-da-seda. Homens como Thomas Jefferson, Lamoignon de Malesherbes, Duhamel du Monceau ou Arthur Young podem ser citados como importantes representantes das Luzes. Nesse sentido, é importante compreender o lluminismo sobretudo como um movimento reformador, oriundo do próprio Antigo Regime, que centrou suas propostas na racionalização do uso da terra, na busca de produtos agrícolas e de origem animal alternativos, na descrição e quantificação das populações e suas atividades, na listagem, classificação e utilização dos chamados três reinos da natureza.

Na realidade do Império luso, as Luzes coincidiram com o decréscimo da produção das minas e com um vácuo momentâneo na eleição de um produto agrícola que suplantasse os demais no mercado internacional. 0 café só se firmaria como o grande cultivo brasileiro depois da Independência. ${ }^{1}$ Além disso, a turbulência política e social nas Antilhas e as guerras na Europa, desde a Revolução Francesa até 1815, afetaram a produção colonial, principalmente da França e da Inglaterra. Essa coincidência ajudou a tornar mais vigorosos os argumentos em favor da exploração racional da natureza brasílica. Desde o século XVIII, a história natural europeia vinha sendo incentivada, entre outras coisas, por suas possibilidades de auxiliar na substituição de produtos importados e na busca de equivalentes locais para vários tipos de indústria e usos. 0 próprio Lineu se vinculava, na Suécia, a esse tipo de pesquisa. ${ }^{2} 0$ que se vê em Portugal, desde 0 período pombalino, é o crescente incentivo ao conhecimento das potencialidades dos produtos brasileiros e, em menor escala, de outras regiões do além-mar. Esse surto investigativo deu origem a diversas experiências, como é o caso da produção de anil, de aclimatação do chá, de experiências com cochonilha, bicho-da-seda e nitreiras artificiais. ${ }^{3}$

Aí se situa 0 Patriota. Grande parte dos temas dos artigos que estampa - sejam traduções ou originais - se circunscreve nesse universo. Na linhagem da Encyclopédie e das memórias publicadas pelas sociedades de homens de letras e de ciências, o jornal brasileiro compartilha da crença de que é possível ensinar a operar máquinas e instrumentos e adestrar gestos e condutas a partir da leitura de textos. Os estudos em história das ciências e das técnicas já vêm chamando a atenção contra a simplificação da compreensão do aprendizado prático. ${ }^{4}$ Pergunta-se com alguma frequência sobre a circulação das obras do período iluminista luso-americano, ${ }^{5}$ mas é necessário expandir a pergunta para indagar se é possível produzir potassa apenas lendo as memórias publicadas por Veloso ou se é viável secar um pântano a partir da leitura de uma memória de 0 Patriota.

As instruções práticas constituem um novo gênero científico, que se expande no século XVIII. A vertente mais estudada pela historiografia é a das instruções de história natural, que incluem botânica, zoologia e mineralogia. Nas artes, porém, os manuais são cada vez mais importantes, e o imenso desenvolvimento das técnicas de gravura possibilitou 0 aperfeiçoamento do aprendizado por meio da leitura e da observação de imagens. ${ }^{6}$

Sem dúvida, também em Portugal e no Brasil cada vez mais os escritos dedicados às ciências e às artes se preocupavam com a publicação de figuras. A Tipografia do Arco do Cego representou um marco importante nas técnicas de confecção e impressão de gravuras. Como vem sendo assinalado, as imagens foram peças fundamentais para os objetivos pedagógicos de Veloso ${ }^{7}$ e, de forma mais ampla, dos projetos ligados à atuação de $\mathrm{D}$. Rodrigo de Sousa Coutinho. 0 editor de 0 Patriota também se esforçou em publicar gravuras, sabendo que acrescentariam qualitativamente em inteligibilidade e didática a qualquer tipo de escrito. Em 0 Patriota, há seis pranchas, ${ }^{8}$ que ilustram os seguintes textos de ciência aplicada, das rubricas "Artes" e "Sciencias": "Memória sobre um alambique mais cômodo" (três estampas), "Notícia acerca de vários carros de transporte" (uma estampa), "Memória sobre os muros de apoio" 
(uma estampa) e "Ensaio sobre algumas propriedades físicas de diferentes madeiras" (uma estampa). Além disso, encontram-se no jornal tabelas, listas e quadros descritivos, que pretendem sintetizar os dados de forma didática para facilitar seu cruzamento e armazenamento. Esse recurso está presente nas tábuas de observação meteorológica da Corte, bem como em diversas descrições de províncias, balanças comerciais, relações de plantas úteis e medicinais, estatísticas populacionais, tabelas gramaticais, resultados de experiências químicas etc.

Apesar de sua importância, as imagens eram caras e relativamente raras. Além do mais, embora acrescentem muito à compreensão, as figuras têm efetividade limitada, assim como os textos. Dois pontos importantes podem ser discutidos a partir dessas reflexões. Em primeiro lugar, o aprendizado prático, o treinamento e a observação são componentes fundamentais para a criação de novos hábitos e maneiras de fazer. Aliado a esse problema, existe, em segundo lugar, o fato de que, para que se estabeleçam novas práticas, é necessário ter instrumentos, materiais e lugares adequados. Assim, talvez a especificidade da ilustração no Brasil possa ser mais bem apreendida se for levada em conta a proveniência das memórias de ciências e artes, e se for identificado até que ponto elas se remetiam a uma prática efetivamente executada, ou se diziam respeito a tentativas de indução de novos procedimentos técnicos e econômicos.

Com relação ao primeiro ponto - 0 aprendizado prático -, o mineralogista Barão de Eschwege deixou um cáustico comentário, que pode ajudar a compreender as estratégias de difusão da ciência útil por parte do Arco do Cego e de 0 Patriota. Sobre as tentativas iniciais frustradas de fabricar ferro no Brasil, o mineralogista germânico afirmou:

Em 1801, um certo João Manso, mulato de nascimento, tendo extraído dos livros alguns conhecimentos químicos e, portanto, segundo o modo de pensar dos portugueses e brasileiros, devia estar habilitado para fabricar ferro, obteve do governo a incumbência de fabricar um novo forno de fundição. ${ }^{9}$

Certamente, muitos dos que atuaram na época haviam tido aprendizado formal acadêmico, o que não foi o caso de João Manso Pereira, mas, para Eschwege, a crítica inclui o bem-nascido Martim Francisco de Andrada, formado em matemática e filosofia natural em Coimbra: João Manso "devia ser auxiliado pelo irmão do conhecido mineralogista Andrada, que fora nomeado inspetor das minas, em virtude de ter traduzido a mineralogia de Bergmann, em Portugal." ${ }^{\prime 10}$ Sem assumir como inteiramente procedente o comentário de Eschwege, ele nos convida a refletir sobre os objetivos das publicações científicas. Elas foram provavelmente concebidas como sendo complementares à atuação das demais instituições lusas, no sentido de formar uma elite para a administração racional e pragmática do Ultramar.

Diferentemente de seu irmão José Bonifácio, Martim Francisco não realizara um tour científico pela Europa. A viagem europeia de José Bonifácio, conhecendo os principais laboratórios e centros metalúrgicos, como a Suécia, que conjugavam estreitamente 0 aprendizado da história natural e da química com as práticas de mineração, foi essencial para sua atuação como professor de metalurgia em Coimbra, intendente das Minas e Bosques do Reino e no laboratório químico da Casa da Moeda de Lisboa. Martim Francisco publicara uma tradução de tratado de mineralogia pelo Arco do Cego. ${ }^{11}$ Já José Bonifácio publicou numerosas obras baseadas em suas próprias experiências. 0 Patriota estampa memória sua, sem título, sobre minas de carvão em Portugal, redigida em Lisboa, em 1809. Essa memória relata as dificuldades e soluções encontradas em alguns casos concretos de extração de minério.

Outro personagem que aliou conhecimentos científicos e experiência prática foi o militar piemontês Carlo Napione, que viria a ser o tenente-general Napion, emigrado para Portugal, a convite de D. Rodrigo de Sousa Coutinho. No Brasil, Napion foi lente da Academia Real Militar e o primeiro diretor da Real Fábrica de Pólvora do Rio de Janeiro, em 1808. Assim como Andrada, ele havia realizado viagens de formação pelos principais centros metalúrgicos europeus. Os dois, aliás, trabalharam juntos em Portugal. Em 0 Patriota, foi publicada a memória "Ensaio sobre algumas propriedades físicas de diferentes madeiras", acompanhada de imagens e tabelas, resultado de parceria com 0 militar Carlos Julião, nascido em Turim. Embora as madeiras não fossem sua especialidade, ele já havia trabalhado com supervisão e avaliação de bosques em Portugal. Na memória, Napion desenvolve e padroniza procedimentos para determinar características de diferentes tipos de madeiras, a fim de se poder determinar melhor seus usos. 
As descrições textuais, a tabela e a gravura da memória poderiam auxiliar na reprodução dessas mesmas experiências com outras madeiras brasileiras.

As áreas de mineração, metalurgia e química foram centrais para a política portuguesa de indução do aprendizado das ciências e das artes. Além dos metais, pedras preciosas e de ferro, interessava aos governantes a produção de pólvora. José Bonifácio já afirmava em sua memória publicada em 0 Patriota: "Pão, pólvora e metais são quem sustenta e defende as nações." ${ }^{\prime 2}$ Os homens de ciência que lidaram com esse tipo de questão se enquadram nos saberes que podem ser qualificados de "politécnicos" e que no Brasil, nas primeiras décadas do século XIX, tinham presença principalmente no corpo dos militares.

Nessa época, a química associava-se também a outras disciplinas e práticas, como a medicina. Um exemplo interessante, e até certo ponto excepcional, é o do médico José Pinto de Azeredo, que, depois de passagem por Coimbra e pela Escócia, realizou análises do ar de diversas localidades do Rio de Janeiro. Aparentemente, seus ensaios se baseavam nas experiências do médico e químico escocês Joseph Black sobre 0 ar fixo. ${ }^{13}$ Azeredo publicou seus escritos em Portugal, antes de chegada da imprensa ao Brasil. Os textos médicos de 0 Patriota, embora se refiram às qualidades do ar, não fazem nenhuma menção à possibilidade de mensuração de seus componentes. ${ }^{14}$

A química em 0 Patriota tem lugar de destaque, principalmente quando aplicada à produção de pólvora ou aos processos de destilação. Há também exemplos de química não aplicada, como é o caso do artigo de Silvestre Pinheiro Ferreira, em defesa da teoria do "calórico", publicado em julho de 1813.

Logo em seu primeiro número, há uma tradução de uma experiência de Frederick Albert Winsor para utilização das propriedades "inflamáveis e explosivas" do açúcar. Nesse caso, como em muitos outros, o jornal estaria dando notícias dos novos procedimentos e invenções testados principalmente na Europa. Ainda nesse primeiro número, foi estampada a tradução de um novo método para refino do açúcar, patenteado na Inglaterra, em 1812, por Louis Germain Constant.

Algumas atividades realizadas pelo laboratório químico de Antonio de Araújo e Azevedo, Conde da Barca, em 1815 foram igualmente divulgadas no periódico, como o funcionamento de um alambique mais econômico, mandado trazer da Escócia pelo diplomata e manipulado por Gaspar Marques, que teria enviado o aparelho para o Rio de Janeiro.

Parte das traduções e notícias extraídas de periódicos e publicações estrangeiros são memórias de história natural aplicada coligidas por Domingos Borges de Barros. Dele são, por exemplo, "Memória sobre o meio de desaguar ou esgotar as terras inundadas", "Noções sobre a cultura e o fabrico do anil", "Notícia sobre o meio de esgotamento de um pântano" e "Memória sobre o café". Barros teve atuação destacada na diplomacia ao longo do século XIX. Assim como alguns membros da elite e da aristocracia das Luzes internacionais, ele ligava seu nome ao favorecimento das ciências e das artes. Não se sabe efetivamente o quanto ele aplicou de suas leituras em sua propriedade na Bahia, mantida com trabalho escravo, chamada Tebaida. Em 0 Patriota, o que se pode ler é fruto de seus contatos e de suas leituras.

A confluência entre história natural e química foi uma das principais características das ciências e das artes na virada do século XVIII para o século XIX. No Brasil, a voga internacional da produção de anil, de corante de cochonilha e de aperfeiçoamento da preparação de açúcar também esteve presente. No entanto, não se atingiu qualidade e quantidade suficiente para que os produtos fossem absorvidos pelo mercado internacional. 0 surto de diversificação foi com o tempo substituído pela onipresença do café, no que se refere à região sudeste.

Nas páginas de 0 Patriota, foi sobretudo Domingos Borges de Barros quem divulgou os artigos internacionais, como foi dito acima. Os responsáveis pelo periódico resgataram também relatos de experiências realizadas por homens de ciência brasileiros, como é o caso da "Memória sobre a cochonilha", redigida por Jacinto José da Silva Quintão, membro da Sociedade Literária do Rio de Janeiro.

No campo das experiências agrícolas, a memória de Manuel Arruda da Câmara sobre o algodoeiro é o melhor exemplo de convergência entre as atividades de plantador e de homem de ciência, nas publicações de 0 Patriota. Câmara havia cursado medicina em Montpellier, entre 1790 e 1791. Lá, estudou com o médico e químico francês Jean-Antoine 
Claude de Chaptal (1756-1832), um dos principais expoentes da "nova química" na França. Seus Éléments de chimie, de 1790, foram traduzidos para inúmeras línguas e circularam amplamente pela Europa e Américas. Em Portugal, parte dessa obra foi traduzida em 1798, e a edição em castelhano circulava igualmente. Chaptal notabilizou-se pela aplicação da química à indústria e à agricultura.

0 texto "Memória sobre a cultura dos algodoeiros", de Manoel Arruda da Câmara, escrito em 1797 e publicado pelo Arco do Cego em 1799, foi novamente publicado, com ligeiras modificações, em 0 Patriota ao longo do ano de 1813. As referências de Câmara a seu mestre demonstram admiração. Câmara chegou a homenageá-lo com um gênero vegetal novo: Chaptalia pekiy, ao qual se refere no Paládio Português (1796) e cita novamente em nota do artigo sobre 0 algodoeiro. ${ }^{15}$

A memória de Câmara trata das melhorias que ele introduziu em diversas fases do cultivo de algodão, inclusive com a construção de máquinas, das quais julga a mais útil uma prensa para ensacar o produto. Da descrição da planta ao plantio, colheita e beneficiamento, o texto também aborda reflexões gerais sobre história natural e distribuição dos vegetais pelo planeta. Arruda da Câmara ${ }^{16}$ teve como meta superar as imperfeições e "erros introduzidos na cultura dos gêneros do Brasil e mais Domínios, sendo todos novos a respeito dos da Europa, e não tendo tido, como os desta, homens sábios que tratassem do seu melhoramento".Um exemplo que escolhe em sua argumentação é o da "cultura da cana e a preparação do açúcar", que, segundo ele, "exigem os mais profundos conhecimentos da Física e da Química" e estariam entregues a homens "néscios e estúpidos". Na virada do século XVIII para o XIX, além das operações para produção de pólvora, entre as quais a extração de salitre, a produção de açúcar foi um caso paradigmático, tanto por causa das inovações implementadas nas colônias britânicas e francesas, quanto pela produção de açúcar a partir de outros vegetais, como a beterraba.

A memória sobre o algodão dá conta de sua atividade como plantador-filósofo. Suas excursões pelos sertões nordestinos, que realizou ao retornar ao Brasil, por ordem de D. Rodrigo, tiveram como objetivo a busca de salitre e metais e o estudo de plantas úteis, principalmente as que pudessem ser transformadas em cordas. Para ambas as atividades, qualificação técnica e estudos teóricos foram imprescindíveis.

Em sua correspondência com seus patronos Sousa Coutinho e Veloso, Câmara reclama que o Ouvidor da comarca do Ceará, querendo ficar bem aos olhos do ministro, teria enviado pessoas mal-formadas para fazerem coletas, seguindo seus passos:

[...] expediu ordens aos Comandantes, Capitães-Mores e Justiças, para que encarregassem aos homens que parecessem mais inteligentes de procurarem a árvore da Quina e salitre; e se recusassem esta determinação, fossem presos, sumariados por desobedientes, e remetidos à cabeça da Comarca; em virtude destas ordens viram-se alguns Naturalistas, feitos por aquele Ouvidor, sem outro conhecimento mais do que o saberem tanger gado, e sem outro prêmio do que a esperança do prometido castigo: daqui procedeu que se iam aproveitar nos lugares de onde eu saía. ${ }^{17}$

Esse tema é mais complexo do que parece à primeira vista. Sem refletir sobre a competição quanto aos serviços prestados à Coroa, representada pelo ministro Sousa Coutinho, a reivindicação de uma espécie de "monopólio" para a atividade científica é um traço bastante revelador do processo de especialização dos naturalistas. Sem dúvida, a formação prévia era um fator fundamental para que o trabalho se adequasse aos padrões internacionais, mas há também movimento no circuito de textos científicos para capacitar pessoas sem habilidades específicas para realização de tarefas como coleta e envio de vegetais e animais e mesmo prospecção básica de terrenos. 0 gênero das "instruções" foi bastante difundido, com já foi afirmado acima. No entanto, o trabalho dos naturalistas foi se tornando cada vez mais minucioso e especializado a ponto de paulatinamente poder prescindir do auxílio de "amadores".

Se comparadas com as observações de servidores sem formação em história natural, as memórias de Câmara se distinguem claramente pela adequação aos padrões internacionais. Por exemplo, o militar Domingos Alves Branco 
Muniz Barreto atuou no sul da Bahia na administração dos aldeamentos indígenas e na tentativa de estabelecer usos mais racionais da floresta. Além disso, deixou um interessante manuscrito com desenhos aquarelados sobre plantas medicinais, no qual estabeleceu um sistema para reconhecimento dos vegetais baseado na aparência das folhas, mais adequado - segundo ele - para mostrar aos índios de que planta se tratava. ${ }^{18}$ Esse manuscrito ficou esquecido durante dois séculos nos arquivos da Academia das Ciências de Lisboa, porém, mesmo que tivesse sido divulgado, dificilmente teria se integrado aos circuitos da botânica, que já eram regidos por convenções relativamente estáveis. Nesse caso, um funcionário qualificado para algumas atividades essenciais não pudera acompanhar a especialização da botânica.

As íntimas relações entre trabalho científico e atividades econômicas não excluíram, entretanto, a presença de pessoas sem formação e, principalmente, daqueles que conservavam as práticas e os conhecimentos tradicionalmente estabelecidos, que seguiam a "cega rotina", tantas vezes criticada em 0 Patriota. 0 próprio Câmara teve que lidar com a dificuldade de implementação de novos procedimentos, como é o caso do ensacador de algodão, além de diversos procedimentos referentes ao plantio e tratamento do produto. 0 pernambucano aborda a questão, fazendo referência à economia que seus inventos poderiam proporcionar. Sobre a máquina de ensacar algodão, afirma: "cheguei a poupar a mão de obra quase na razão de 20:1." Ele pressupõe, em sua memória, que os homens tenderiam a agir de acordo com uma racionalidade universal, sempre visando o lucro e a economia de braços. Este ponto é crucial em diversas memórias publicadas na revista, como aquelas compiladas por Domingos Borges de Barros. Em uma descrição sobre o "esgotamento de um pântano", realizado por um homem chamado Charpentier, em Saint-Denis, nas proximidades de Paris, o diplomata refletiu sobre o trabalho no Brasil. Ele afirmou que a drenagem de pântanos necessitaria de uma máquina muito simples, um parafuso de Arquimedes. Apesar da facilidade de execução, no Brasil essa máquina era muito pouco empregada, continuava ele, "pela mesma fatalidade porque não são outras muitas, e não sabemos trabalhar, senão à força de braços". ${ }^{19}$

Portanto, pode-se avançar que o esforço didático de 0 Patriota não consistia apenas no ensino da utilização das máquinas e procedimentos descritos nas memórias publicadas. Tratava-se igualmente da difusão de um tipo de lógica econômica e científica. A ciência útil busca equilibrar gastos, poupar tempo e trabalho, aumentar a produtividade, planejar a médio prazo, pois, de acordo com esses homens das Luzes, seria esse o caminho para atingir um mais elevado nível civilizacional e a prosperidade.

As memórias publicadas em 0 Patriota trazem aos leitores do Brasil o léxico internacional referente às ciências e às artes. Trazem também uma maneira específica de abordar as questões e de apresentar seu conteúdo. Muitos textos apresentam detalhados procedimentos técnicos, longas descrições topográficas, linguagem matemática. Além disso, existe no período uma maneira nova de organizar as informações em tabelas, quadros e listas, que servem como ferramenta didática importante.

Há, em 0 Patriota, muitos artigos dedicados à "hidrografia", provavelmente organizados a partir da atuação de engenheiros militares. Os saberes ligados ao conhecimento da costa e à demarcação de limites e fronteiras possuem uma dinâmica específica e se desenvolveram enormemente ao longo do século XVIII. Segundo Íris Kantor, os saberes ligados à cartografia tiveram importância estratégica no pacto estabelecido entre os poderes metropolitanos e as elites regionais. A unidade territorial do Brasil imperial foi, portanto, gestada nas décadas anteriores e incluiu a ação de oficiais militares, engenheiros e cartógrafos, portadores de conhecimentos e práticas especializados. ${ }^{20} 0$ periódico estampa textos bastante técnicos, o que demonstra a legitimidade fora de dúvida desses temas.

As matérias relativas à descrição do território aparecem sob diversas rubricas, incluindo "estatística", "história" e "topografia". O Patriota publicou textos corográficos mais tradicionais, produzidos ao longo do século XVIII, e também descrições de outro tipo, chamadas de "estatísticas". Os objetos ligados ao tema eram as diferentes capitanias, mesmo as mais distantes, suas populações, suas atividades produtivas, os caminhos e rotas que as ligavam ao restante do território brasileiro, incluindo as regiões ao Norte. 0 editor Araújo Guimarães sintetizou, em uma memória da rubrica "História", os objetivos gerais da revista, no que se refere a esse gênero de descrição: 
Sendo o principal objeto deste Periódico fazer conhecer este continente, tão ignorado, ou tão desfigurado por aqueles que às cegas, ou prevenidos, têm escrito a seu respeito; e desejando aproveitar todas as notícias verídicas que chegam à nossa mão, temos hoje a satisfação de apresentarmos ao Público os progressos da povoação e civilização dos lugares mais centrais, há pouco desertos, ou infestados por nações bárbaras e ferozes. [...] O que imos referir é fundado em documentos autênticos, e da maior fé. Temos consultado papéis originais, e firmamos com o selo da verdade a nossa exposição. ${ }^{21}$

As descrições chamadas de estatísticas organizavam as informações a partir de divisões disciplinares novas, como o nascente campo da economia ou o estudo quantitativo das populações. De todo modo, nesse momento de centralidade política da Corte no Rio de Janeiro, a tendência geral dos textos inseridos em 0 Patriota é a da análise detalhada das condições específicas de cada região. Os textos de descrição das diferentes capitanias, seja na forma de corografias ou de relatórios estatísticos, demonstram a preocupação do editor em inventariar as diferenças e peculiaridades regionais, com o objetivo de conhecer as possibilidades para seu desenvolvimento. Não há, no entanto, nenhum tipo de defesa dos regionalismos; ao contrário, os atributos específicos de cada localidade deveriam ser racionalizados e administrados de modo a garantir uma melhor extração de suas riquezas e uma conexão mais eficaz com os locais de escoamento dos produtos. 0 ponto de vista do periódico parte do centro de poder, do soberano. As particularidades locais apenas se tornavam relevantes quando referidas a uma potencial utilidade para o Império.

Parte dessas memórias se remete a experiências de militares e funcionários da Coroa, empenhados na administração de territórios disputados com indígenas, e narra uma espécie de processo de apropriação do interior. Araújo Guimarães, depois de descrever atividades do capitão Francisco José Pinto (de Magalhães), conclui:

A perspectiva que começa a aparecer, do Brasil comunicado por fáceis estradas, e pela navegação de grandes rios; a consoladora esperança de ver tantas nações bárbaras, que infestam este Continente, despidas da natural fereza, tornarem-se sociáveis, e aumentarem o número de vassalos de S. A. R.; a ideia lisonjeira da prosperidade da agricultura, do estabelecimento das artes, da extensão do Comércio; não são já sonhos de um patriota, a quem o amor de seu país inflama, e anima [...]. ${ }^{22}$

A Breve descrição topográfica e estatística da capitania do Espírito Santo, de Francisco Manuel da Cunha, registra a experiência de seu autor, como escrivão da Junta da Fazenda da Capitania do Espírito Santo. Aí se encontra uma descrição da configuração natural do lugar, com seus principais rios e acidentes geográficos. Porém, o mais relevante nessa memória é a enumeração dos principais representantes locais da Coroa e dos edifícios públicos, militares ou religiosos, que representariam o estado de inclusão de cada povoamento ou vila nas redes comerciais e viárias de ligação com as demais capitanias. 0 estado de inclusão dos indígenas na vida mercantil e civil também é descrito de maneira pormenorizada. Enfim, o que importa é verificar a presença - mesmo que precária - dos agentes da Coroa e do comércio, comprovando, assim, que se trata de um Império. ${ }^{23}$

0 Patriota dá notícia das estradas e caminhos, das vias de comunicação. Sobre o tema do deslocamento por terra - preferível ao deslocamento por mar - entre Maranhão e Rio de Janeiro, em uma notícia sobre novas estradas, o editor comentou a relevância do tema:

Os Representantes do Nosso Augusto Soberano, animados daquele fervoroso desejo de felicitar os povos do Brasil, que inflama o Seu coração, tem acordemente empenhado as suas forças nesta briosa porfia. Em vez de correspondências particulares em extremo dispendiosas, e só ao alcance dos mais abonados, se estabelecem fáceis e frequentes comunicações, pelas quais não só se expeçam avisos de comércio, mas até notícias familiares. O que parece logo da maior importância é a correspondência com a Corte, e esta se consegue facilmente dirigindo-se do Maranhão à Bahia, e desta Capitania à do Rio de Janeiro. ${ }^{24}$

O Patriota publica também "roteiros" de várias viagens pelo Brasil. Por exemplo, há o "Roteiro para seguir a melhor estrada do Maranhão para a Corte do Rio de Janeiro", ${ }^{25}$ no qual são elencados os lugares por onde passar, a fim de 
realizar uma viagem mais direta e sem percalços. A autoria não é revelada, mas certamente se trata de alguém que efetivamente realizou tal deslocamento.

Desse modo, muitas matérias de 0 Patriota expõem conhecimento útil, seja no campo da matemática, do mapeamento da costa, da agricultura ou da geografia. Os leitores também podiam percorrer artigos políticos, narrativas históricas e poesia. ${ }^{26}$ Esse conjunto serviria para a educação dos "patriotas", daqueles que, ao louvarem a presença do soberano no Brasil, reivindicavam para si lugar no mundo das letras, das ciências e da civilização.

Cada ramo das ciências ou cada tipo de conhecimento tinha, no entanto, sua especificidade e sua forma particular de pleitear utilidade. Textos ou informações antigos podiam trazer a público elementos relevantes, e por isso mereciam ser estampados por 0 Patriota. A ênfase do periódico era, no entanto, a atualidade. Conhecimentos que circulavam há séculos ganhavam relevância ao serem expostos de maneira organizada e legitimada por pessoas de reconhecida autoridade. Por exemplo, 0 artigo "Plantas medicinais indígenas de Minas Gerais" traça lista de vegetais e seus usos estabelecida pelo "Físico das Tropas", Luiz José de Godoy Torres. As plantas e propriedades listadas eram já conhecidas tanto pelos populares quanto por naturalistas, médicos e cirurgiões que atuavam na região. A diferença da memória de Godoy é que ela classifica, descreve e nomeia as espécies vegetais pelo sistema lineano, usando 0 latim. ${ }^{27}$

Outra memória sobre matéria médica teria sua utilidade assegurada pelo fato de sintetizar informações que estavam dispersas e arranjá-las em colunas, o que facilitaria o seu uso. Na primeira coluna, intitulada "Plantas", indica-se o nome vulgar do vegetal. A segunda coluna, "Descrição e qualidades", descreve o uso, a forma e outras denominações, inclusive o nome científico, quando é sabido. A última coluna indica os "Lugares" nos quais são encontrados. ${ }^{28}$

0 conhecimento útil em 0 Patriota admite diferentes formas, permeia temas diversos e adota níveis de abordagem díspares. Da unidade territorial, representada pelos mapas, estradas e - indiretamente - pela pólvora, às plantas medicinais e métodos de cultivo do algodão, o periódico reúne escritos da elite dos homens de ciência brasileiros e portugueses. Reúne também um apanhado do que havia de mais atualizado na Europa, principalmente no que se refere à história natural aplicada. Tratava-se, assim, de uma espécie de jornal enciclopédico, nos moldes internacionais.

De certo modo típico, 0 Patriota foi também único. A densidade e quantidade dos artigos de ciências e artes impressionam. A publicação foi um dos resultados palpáveis das políticas de D. Rodrigo de Sousa Coutinho para 0 favorecimento das atividades científicas no Brasil. Araújo Guimarães reuniu trabalhos de grande parte da chamada "geração de 1790", ${ }^{29}$ além de trazer contribuições anteriores, identificadas ao estilo ilustrado do grupo.

Os artigos que figuram em 0 Patriota correspondem, em muitos casos, a atividades e experiências realizadas por seus próprios autores, em geral militares, funcionários da Coroa ou homens de algum modo ligados à administração do Império luso. Sua formação era inteiramente desigual. Alguns tinham inserção internacional e adotavam práticas reconhecidas pelas instituições europeias. Outros, menos cosmopolitas, haviam estudado em Coimbra, onde aprenderam a fazer "ciência útil". As viagens, as traduções e as leituras faziam igualmente parte da formação desses autores. No Brasil, de dimensões continentais, os conhecimentos mais ou menos livrescos podiam ganhar uma nova dimensão e servir para classificar plantas, extrair corante de cochonilha, enviar amostras de minerais para o ministro e avaliar os usos dos produtos locais.

Quantos eram esses homens de letras e ciências? Poucos. O Patriota conseguiu completar dois anos de existência porque dispunha do aparato da Impressão Régia e das redes institucionais de Araújo Guimarães. A lista dos subscritores inclui grandes personagens da Corte e alguns comerciantes esclarecidos. ${ }^{30}$ Quem lia o periódico? Quem era capaz de ler poesia e hidráulica? Os periódicos especializados só começam realmente a figurar no mercado editorial na segunda metade do século XIX. 0 enciclopedismo de 0 Patriota adequava-se a um universo letrado sem especialização. 
Os autores das memórias também podiam pertencer a esse mundo. Poucas são as memórias efetivamente exclusivas a um grupo profissional.

A imprensa científica especializada posterior será um elemento essencial para a formação dos homens de ciência como grupo no Brasil. Paralelamente, vão se formar e consolidar outros elementos constitutivos da atividade científica profissional, como a criação de laboratórios, coleções, bibliotecas e hospitais. Em 1813 e 1814, não se tratava exatamente disso. Buscava-se legitimar o espaço público das letras e das ciências no Brasil. Com o soberano no Rio de Janeiro, o espaço americano mudou de qualidade, passou a sediar o poder.

O Patriota buscava difundir maneiras não só de fazer ciência, mas de conceber a ciência. Suas páginas foram um veículo importante para introduzir temas, mostrar formas de solucionar problemas, homogeneizar o vocabulário dos grandes homens esclarecidos e vincular prestígio e Luzes.

\section{Notas e referências bibliográficas}

Lorelai Kury é doutora em História pela École des Hautes Études en Sciences Sociales, França, e pesquisadora e professora do Programa de Pós-Graduação em História das Ciências e da Saúde da Casa de Oswaldo Cruz.É pesquisadora do CNPq. E-mail: Iolakury@gmail.com

1 MARQUESE, Rafael de Bivar. A llustração luso-brasileira e a circulação dos saberes escravistas caribenhos: a montagem da cafeicultura brasileira em perspectiva comparada. História, Ciências, Saúde - Manguinhos, v. 16, n. 4, p. 855-880, out.-dez. 2009.

2 KOERNER, Lisbet. Linnaeus: nature and nation. Cambridge: Harvard University Press, 1999.

3 Cf. PESAVENTO, Fábio. Um pouco antes da Corte: a economia do Rio de Janeiro na segunda metade do Setecentos. Tese (Doutorado em Ciências Econômicas) - Universidade Federal Fluminense, Niterói, 2009; e FERRAZ, Márcia. A produção do salitre no Brasil colonial. Química Nova, v. 23, n. 6, 2000.

4 Ver, entre outros: BRET, Patrice. L'État, l'armée, la science: l'invention de la recherche publique en France (1763-1830). Rennes: Presses Universitaires, 2002; MOKYR, Joel. Knowledge, enlightenment, and the industrial revolution: reflections on the Gifts of Athena. History of Science, v. 45, p. 185196, 2007; LICOPPE, Christian. La formation de la pratique scientifique: le discours de l'expérience en France et en Angleterre (1630-1820). Paris: La Découverte, 1996.

5 Por exemplo, WEGNER, Robert. Livros do Arco do Cego no Brasil colonial. História, Ciências, Saúde - Manguinhos, v. 11, suplemento 1, p. 131-140, 2004.

6 Ver, por exemplo, DOLAN, Brain. Pedagogy through print: James Sowerby, John Mawe and the problem of colour in early nineteenth-century natural history illustration. British Journal for the History of Science, v. 31, p. 275-304, 1998. Ver a discussão em: WISE, Norton. Making visible. Isis, v. 97, p. 75-82, 2006.

7 FARIA, Miguel. A imagem útil. Lisboa: Universidade Autônoma de Lisboa, 2002.

8 Falta uma imagem no exemplar da Biblioteca Nacional do Rio de Janeiro. A coleção Guita e José Mindlin possui exemplar completo.

9 ESCHWEGE, Pluto Brasiliensis, 1833 apud FILGUEIRAS, Carlos. João Manso Pereira, químico empírico do Brasil colonial. Química Nova, v. 16, n. 2, 1993. p. 157.

$10 \quad$ Ibidem, loc. cit.

11 Sobre a tradução de Martim Francisco, ver LUNA, Fernando; KURY, Lorelai. Enlightenment chemistry translated by a Brazilian man of science in Lisbon. Ambix, no prelo.

10 SILVA, José Bonifácio de Andrada e. Memória do desembargador José Bonifácio de Andrade. 0 Patriota, jul. 1813. p.13.

11 Ver PINTO, José Serrano et al. 0 médico brasileiro José Pinto de Azeredo (1766?-1810) e 0 exame químico da atmosfera do Rio de Janeiro. História, Ciências, Saúde - Manguinhos, v. 12, n. 3, p. 617-673, set.-dez. 2005.

12 Sobre os textos médicos de 0 Patriota, ver KURY, Lorelai. Descrever a pátria, difundir o saber. In: (1813-1814). Rio de Janeiro: Fiocruz/Biblioteca Nacional, 2007.

(Org.). Iluminismo e Império no Brasil. O Patriota

13 CÂMARA, Manoel Arruda da. Obras reunidas. Org. José Antonio Gonsalves de Mello. Recife: Fundação de Cultura da Cidade do Recife, 1982. p. 104 e p. 160; e CÂMARA, Manoel Arruda da. Memória sobre o algodoeiro. O Patriota, jan.-mar. 1813.

14 CÂMARA, Manoel Arruda da. Memória sobre a cultura dos algodoeiros. In: Fundação de Cultura da Cidade do Recife, 1982. p. 113.

17 CÂMARA, Manoel Arruda da. Carta a D. Rodrigo de Sousa Coutinho, 1799. In: ___. Obras reunidas. Org. José Antonio Gonsalves de Mello. Recife: Fundação de Cultura da Cidade do Recife, 1982. p. 243. Ver também "Carta de Manuel Arruda da Câmara a Frei José da Conceição Veloso". 02/06/1799. Ms. (cópia) Museu Paulista.

18 Segundo o próprio Muniz Barreto, a pesquisa sobre os usos que os indígenas faziam das plantas medicinais era apenas um pretexto para travar contato com populações refugiadas no mato. Ver BARRETO, Domingos Alves Branco Muniz. 0 feliz clima do Brasil. Rio de Janeiro: Dantes, 2008.

19 BARROS, Domingos Borges de. Notícia sobre o meio que se seguiu no esgotamento de um pântano. 0 Patriota, dez. 1813. p. 3-5. 
KANTOR, Íris. Cultura cartográfica e gestão territorial na época da instalação da corte portuguesa. In: KURY, Lorelai; GESTEIRA, Heloísa (Org.). Ensaios de história das ciências no Brasil: das Luzes à nação independente. Rio de Janeiro: EdUERJ, [no prelo].

21 GUIMARÃES, Manuel Ferreira de Araújo. Notícias das novas povoações de S. Pedro de Alcântara e S. Fernando, civilização da nação Macamecran, estrada para o Pará. 0 Patriota, set. 1813. p. 61.

22 Ibidem, p. 68. Sobre a conjuntura da política oficial com relação aos índios, ver CUNHA, Manuela Carneiro da. Pensar os índios: apontamentos sobre José Bonifácio. In: . Antropologia do Brasil. Mito, história, etnicidade. São Paulo: Brasiliense, 1986.

23 Essa região vivia momento conturbado, com a formação de uma Junta de Civilização dos Índios para atuar no Rio Doce, na esteira da Carta Régia de 1808 , que condenava os Botocudos ao cativeiro.

24 GUIMARÃES, Manuel Ferreira de Araújo. Notícia de novas estradas do interior, para facilitar a comunicação das Capitanias Centrais. 0 Patriota, ago. 1813. p. 68.

25 ROTEIRO para seguir a melhor estrada do Maranhão para a Corte do Rio de Janeiro. O Patriota, dez. 1813. p. 6-8.

26 Ver GUIMARÃES, Manoel L. Salgado. As Luzes para o Império: história e progresso nas páginas de 0 Patriota. In: KURY, L. (Org.). Iluminismo e Império no Brasil. 0 Patriota (1813-1814). Rio de Janeiro: Fiocruz/Biblioteca Nacional, 2007; e ALCIDES, Sérgio. 0 lado B do neoclassicismo luso-brasileiro: patriotismo e poesia no "poderoso império". In: KURY, L. (Org.). Iluminismo e Império no Brasil. 0 Patriota (1813-1814). Rio de Janeiro: Fiocruz/Biblioteca Nacional, 2007.

27 TORRES, Luiz José de Godoy. Plantas medicinais indígenas de Minas Gerais. O Patriota, p. 62-73, mai.-jun. 1814.

28 MAPA das plantas do Brasil, suas virtudes, e lugares em que florescem. Extraído de ofícios de vários médicos e cirurgiões. 0 Patriota, p. 3-13, jul.-ago. 1814.

29 MAXWELL, Kenneth. A geração de 1790 e a ideia do império luso-brasileiro. In: Chocolate, piratas e outros malandros: ensaios tropicais. São Paulo: Paz \& Terra, 1999

30 FERREIRA, Tania Bessone. Redatores, livros e leitores em 0 Patriota. In: KURY, L. (Org.). Iluminismo e Império no Brasil. 0 Patriota (1813-1814). Rio de Janeiro: Fiocruz/Biblioteca Nacional, 2007.

[Recebido em agosto de 2010, aprovado para publicação em novembro de 2011] 